\title{
Comparative Study of Ripening Related Gene Expression and Postharvest Physiological Changes between Astringent and Nonastringent Persimmon Cultivars
}

\author{
Jingjing Kou, Zhihui Zhao, and Wenjiang Wang \\ College of Horticulture, Hebei Agricultural University, Baoding 071000, People's Republic of China \\ Chuangqi Wei and Junfeng Guan \\ Institute of Genetics and Physiology, Hebei Academy of Agricultural and Forestry Science, Shijia \\ Zhuang 050051, People's Republic of China \\ Christopher Ference \\ Department of Plant Pathology, University of Florida, 2550 Hull Road, Gainesville, FL 32611
}

AdDITIONAL IndEx wORDs. astringency, cell wall enzyme, ethylene, postharvest quality, real-time polymerase chain reaction, RT-PCR

\begin{abstract}
Mopan' persimmon (Diospyros kaki Thunb.) is a traditional astringent cultivar of persimmon and 'Yoho' persimmon $(\mathrm{D} . \mathrm{kaki})$ is a newly introduced Japanese nonastringent type of cultivar in northern China. Studies were conducted to investigate the physiological changes and expression of ripening-related genes in the postharvest process at different periods under the effects of endogenous ethylene in both cultivars. Persimmons were harvested and stored under room temperature for 20 days. An analysis of physiological changes showed significant differences between the two cultivars. Total soluble solids declined in 'Mopan' fruit, whereas those in 'Yoho' fruit increased during storage. Firmness, color, index of absorbance difference, total and soluble tannin contents, ethylene production, and respiration rates showed the same trend, but these values vary by cultivar. 'Mopan' fruit softened rapidly after harvest and attained edible quality in 20 days, with an increased rate of softening accompanied by increased expression of ripening-related genes. In contract, 'Yoho' fruit softening occurred slowly and did not soften even after 20 days, with minimal accumulation of the ripening-related genes. The information obtained from this study demonstrates that cell wall-hydrolyzing enzymes, the de-astringent process, and endogenous ethylene have critical roles in postharvest ripening, gene expression, and physiological property changes of 'Mopan' and 'Yoho' persimmon fruit during storage.
\end{abstract}

Persimmon (Diospyros kaki) is a popular fruit in China due to its flavor and nutritional value with various cultivars. China is the leading region for persimmon agriculture, with $91.15 \%$ of the cultivation area and $73.46 \%$ of the production volume of the world (Food and Agriculture Organization of the United Nations, 2016), thus making this fruit one of the most cultivated and consumed types of produce, especially in Hebei province, where they are particularly suited to the climate. After Guangxi, Hebei province is the second-largest producer of persimmon among Chinese provinces, with $\approx 600$ million $\mathrm{kg}$ of conventional persimmon produced in 2016 (Ministry of Agriculture of the People's Republic of China, 2018). Due to the expansion of persimmon production in recent decades, the total persimmon harvest was reported to have a value of 1.2 billion international

Received for publication 15 Jan. 2020. Accepted for publication 2 Mar. 2020. Published online 30 March 2020.

This work was supported by the Science and Technology Development Research Projects of Hebei Province, People's Republic of China (no. 17226816D), and by Postdoctoral Fellowship Funds of Hebei Academy of Agriculture and Forestry Sciences.

J.K. and C.W. contributed equally to this work.

W.W. and J.G. are the corresponding authors. E-mail: wangwj65@126.com or junfeng-guan@263.net.

This is an open access article distributed under the CC BY-NC-ND license (https://creativecommons.org/licenses/by-nc-nd/4.0/). dollars (Int\$) in 2014, and it has increased rapidly in the most recent 10 years (Food and Agriculture Organization of the United Nations, 2018). Therefore, the outlook for persimmon production continues to be positive.

Persimmon is classified as astringent or nonastringent cultivars depending on whether the fruit loses astringency on the tree at maturity (Mo et al., 2016). 'Mopan' persimmon is a pollination-constant astringent (PCA) type and a late-ripening (late November) astringent persimmon; it is the most common persimmon cultivar in Hebei province. It is grown successfully in the humid continental climate and produces very large fruit $(\approx 400 \mathrm{~g})$ that have a soft and juicy flesh filled with vitamins, fiber, and antioxidants; it is also used in traditional Chinese medicine (Chen et al., 2008; George and Redpath, 2008). 'Yoho' persimmon is a Japanese pollination-constant nonastringent (J-PCNA) type and a midripening (early November) nonastringent persimmon; it is a new cultivar that was released in the 1990s in Japan (Yamane et al., 1991) and introduced in Hebei province in recent years. The 'Yoho' fruit has a moderate size and is primarily available at local markets; it became popular due to its improved characteristics, such as increased juiciness, high sugar content, low number of seeds, and few brown specks on the flesh (Yamada et al., 2012).

The two cultivars have obviously different postharvest properties. 'Mopan' persimmon fruit is prone to rapid softening 
after harvest, leading to limited shelf life. In the short harvest season, large numbers of postharvest losses occur when 'Mopan' persimmon fruit are in abundant supply at the market. Therefore, 'Mopan' persimmon fruit are usually harvested at an early stage of maturity for commercial reasons (handling, longdistance transport). However, less mature fruit usually exhibits poor sensory quality and negative consumer acceptability during marketing. It is possible to control ripening and softening of 'Mopan' persimmon fruit by using postharvest management practices including $\mathrm{CO}_{2}$ (Zhang et al., 2012) and 1-methylcyclopropene (1-MCP) vacuum packaging (Watkins, 2008). In contrast, 'Yoho' fruit loses astringency naturally and is characterized by firm texture, long shelf life, and no treatment requirements for edibility (Yakushiji and Nakatsuka, 2007). In addition, as a new cultivar in Hebei, Yoho persimmon can be grown throughout the province due to its high yield, good field performance, and strong adaptability.

Fruit softening mainly results from cell wall degradation and the changes in cell wall composition, which are determined by a group of cell wall-modifying enzymes, including pectin methylesterase [PME (EC 3.1.1.11)], polygalacturonase [PG endo-type (EC 3.2.1.15); exo-type (EC 3.2.1.67)], $\beta$-galactosidase $[\beta$-Gal (EC 3.2.1.23)], and xyloglucan endotrasglucosylase/ hydrolase [XTH (EC 2.4.1.207)] which have been isolated in persimmon fruit. In previous studies, the action of ethylene may also affect the gene expression of cell wall degradation-related enzymes during persimmon fruit softening (Wang et al., 2017; Zhu et al., 2012).

Loss of astringency is another typical character of 'Mopan' persimmon fruit during ripening. The mechanism of natural deastringency of the astringent type is related to the coagulation of soluble tannins into insoluble tannins, which is quite different from that of the nonastringent type (Mo et al., 2016). Nonastringent type (J-PCNA types) persimmon fruit, like 'Yoho' fruit, loses astringency naturally by diluting the soluble tannins through fruit growth due to the cessation of the development of tannin cells in the early stages of fruit development (Yonemori and Matsushima, 1985). 'Yoho' fruit does not require any treatments for edibility after harvest, which makes it more desirable for consumers. Acetaldehyde has an important role in the coagulation of soluble tannins because it converts them into insoluble tannins (Taira et al., 2001; Tanaka et al., 1994). The synthesis of acetaldehyde can be catalyzed by both pyruvate decarboxylase [PDC (EC 4.1.1.1)] and alcohol dehydrogenase [ADH (EC 1.1.1.1)], with PDC converting pyruvate into acetaldehyde and with ADH involved in the reversible interconversion of ethanol and acetaldehyde (Strommer, 2011; Yamada et al., 2002). DkADH and DkPDC are considered to be the most important candidates for the different developmental stages of different types (PCA, J-PCNA, C-PCNA) (Mo et al., 2016) and the de-astringency by $\mathrm{CO}_{2}$ and ethylene treatment (Min et al., 2012).

Ethylene, as one of the most important phytohormones, is recognized as having an essential part in fruit ripening, and some reports have shown that small amounts of exogenous ethylene could rapidly accelerate the ripening process (Saltveit, 1999). The ethylene response is regulated at multiple levels, from hormone synthesis and perception to signal transduction and transcriptional regulation. The pathway for ethylene signal transduction involves ethylene receptors ethylene response $(E T R)$ and ethylene response sensor $(E R S)$, constitutive triple response $(C T R)$, ethylene insensitive (EIN2 and EIN3), and ethylene response factor $(E R F)$. Previous studies indicated that
DkETR1, DkETR2, DkCTR1, DkERS1, DkERF19, and $D k E R F 22$ have a central role in persimmon during fruit ripening (Pang et al., 2007; Wang et al., 2017) and are important for the postharvest stage of the fruit.

Although the amount of information already reported about the fruit changes after 1-MCP and $\mathrm{CO}_{2}$ treatment (Guo et al., 2006; Kato, 1990), the normal ripening processes of 'Mopan' and 'Yoho' persimmon fruit are still poorly understood. Hebei province is the main producing area of 'Mopan' astringent persimmon. In addition, 'Yoho' performed very well after being introduced to Hebei, and it was found to be suitable for development as the main nonastringent cultivar with higher economic value than 'Mopan'. These two cultivars are mainly cultivated by small-scale farmers in Hebei and are an important source of income for such many resource-constrained farmers. Fruit quality and postharvest transportation are essential for the economic viability of both cultivars. Therefore, a systematic and full understanding of the fruit's natural physiological development and the ripening-related gene expression of fruit after harvest could contribute to higher fruit availability. The objectives of this study were to 1) investigate the natural fruit ripening process and the major physiological property changes of 'Mopan' and 'Yoho' fruit; and 2) understand the molecular regulation and mechanisms of the normal ripening and deastringency changes by investigating the associated gene expressions during 'Mopan' and 'Yoho' fruit storage.

\section{Materials and Methods}

Plant materials and growth conditions. Commercially mature fruit of two cultivars, Mopan and Yoho (Fig. 1), of persimmon fruit were harvested on 22 Oct. 2016 at commercial maturity from a commercial orchard located in Shijiatong, Hebei, China. Standard commercial cultural practices were applied as required for the fruit trees. After harvest, the fruit were collected into bags and immediately transported to the Institute of Genetics and Physiology, Hebei Academy of Agriculture and Forestry Science (Shijiazhuang, Hebei, China) within $4 \mathrm{~h}$ in cooler boxes with ice $\left(0{ }^{\circ} \mathrm{C}\right.$ and $90 \%$ to $95 \%$ relative humidity) and stored at 22 to $25{ }^{\circ} \mathrm{C}(65 \%$ relative humidity) for the following experiments. Similar fruit without physical injuries were selected according to their uniformity of shape, color, and size. The mean sample weights of 'Mopan' and 'Yoho' persimmon fruit were $( \pm$ SD) $240.1 \pm 15.02$ and $147 \pm$ $11.15 \mathrm{~g}$, respectively.

Fruit STORAGE. After pre-cooling in air to release field heat ( 22 to $25^{\circ} \mathrm{C}$ and $65 \%$ relative humidity), 'Mopan' and 'Yoho' persimmon fruit (900 fruit for each cultivar) were randomly divided into three groups, with 300 fruit in each group. Fruit in each group (300 fruit) were placed into commercial cardboard boxes ( 25 fruit/box) and transferred to each storage shelf room and stored at 22 to $25{ }^{\circ} \mathrm{C}$ and $65 \%$ relative humidity for up to $20 \mathrm{~d}$. Three different shelf rooms (300 fruit for each cultivar in each room) with the same storage conditions were used. Samples were taken at $0,4,7,10,15$, and $20 \mathrm{~d}$ of storage for measurements of various physiological properties and for selected gene analysis.

FRUIT COLOR ANALYSIS, TOTAL SOLUBLE SOLIDS MEASUREMENTS, AND MATURITY ASSESSMENTS. Fifteen to 20 fruit from each sample were marked at the beginning of the experiment. Samples were continuously monitored during ripening by performing optical measurements at each time point to track the progress of the color change. The fruit surface color was 

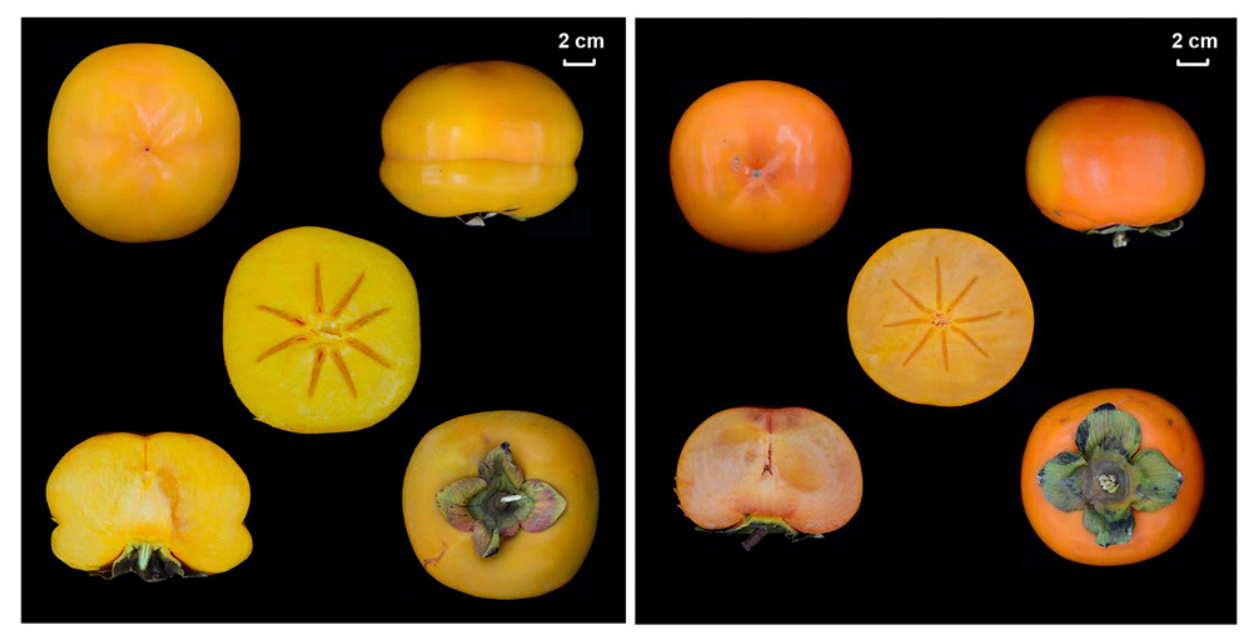

'Mopan'

'Yoho'

Fig. 1. Photograph of pollination-constant astringent (PCA) type persimmon 'Mopan' and Japanese pollinationconstant nonastringent (J-PCNA) type persimmon 'Yoho' fruit at maturity.

measured with a colorimeter (CR400; Minolta, Ramsey, NJ) at two evenly distributed equatorial sites of each fruit. $L^{*}$ (lightness), $a^{*}$ ('- green' to '+ red'), and $b^{*}$ ('- blue' to '+ yellow') values were recorded and the results were expressed as $L$-value (lightness), chroma $\left(\mathrm{C}=\left[\left(\mathrm{a}^{*}\right)^{2}+\left(\mathrm{b}^{*}\right)^{2}\right]^{0.5}\right.$, color intensity), and hue angle $\left(\mathrm{h}^{\circ}=\arctan \left(\mathrm{b}^{*} / \mathrm{a}^{*}\right)\right.$, actual color $)$. Chroma and hue angle indicate the intensity of the color saturation (dull to vivid) and color changes as red-purple $\left(0^{\circ}\right)$, yellow $\left(90^{\circ}\right)$, bluishgreen $\left(180^{\circ}\right)$, and blue $\left(270^{\prime}\right)$ (Amal et al., 2010).

For each sample, after skin removal, the flesh was sliced into cubes $\left(\approx 1 \mathrm{~cm}^{3}\right)$. Cubes were homogenized in a stainless-steel blender and then centrifuged for $10 \mathrm{~min}$ at $2500 \mathrm{~g}$. Total soluble solids (TSS) were then determined from the juice using a digital refractometer (model 3810 PAL-1; Atago, Tokyo, Japan); 15 to 20 fruit per group were used at storage days $0,4,7$, 10,15 , and 20 , and the experiment was replicated three times.

For each cultivar, persimmon maturity was determined individually and nondestructively with a handheld delta absorbance (DA) meter (Sinteleia, Bologna, Italy), which is a portable device based on visible (vis)/near-infrared (NIR) spectroscopy (Ziosi et al., 2008). The DA meter was developed by using the absorbency properties of chlorophyll to measure the chlorophyll content in the skin of the fruit. The chlorophyll content of a fruit is a precise index of the ripeness of that fruit. The instrument provides an index of absorbance difference $\left(I_{A D}=\right.$ $\left.\mathrm{Abs}_{670}-\mathrm{Abs}_{720}\right)$, which is calculated as the absorbance at 670 $\mathrm{nm}\left[\mathrm{Abs}_{670}\right.$ (absorbance peak for chlorophyll)] minus the absorbance at $720 \mathrm{~nm}\left[\mathrm{Abs}_{720}\right.$ (background of the spectrum)]. The $I_{A D}$ index was measured by averaging the values recorded on the equatorial region of the two opposite sides (blushed and unblushed sides; 60 fruit from each group were marked at the beginning of the experiment).

Fruit FIRMNESS MEASUREMENT. Fifteen to 20 'Mopan' and 'Yoho' persimmon fruit were taken at storage days $0,4,7,10$, 15 , and 20 from each group. The firmness of persimmon flesh was measured on two equidistant peeled $\left(\approx 1 \mathrm{~cm}^{2}\right.$ of the skin was removed) sites, on the blushed and unblushed side, and on the equatorial axis of each fruit using a digital hardness tester (GY-4; Handpi, Zhejiang, China) fitted with a head $7.9 \mathrm{~mm}$ in diameter. The hardness tester was set perpendicularly to the surface of the fruit and the indenter pressed into the pulp evenly and stopped when reaching the mark $(10 \mathrm{~mm})$; the results were expressed in Newtons.

Determination of SOluble AND TOTAL TANNINS. Persimmon slices were taken on storage days 0,4 , 10 , and 20 from 15 to 20 fruit in each group and ground to a fine powder using liquid nitrogen before total and soluble tannin extraction. Different solutions were used for total and soluble tannin extraction. Total tannins were extracted by 0.56 $\mathrm{N} \mathrm{HCl}$ and boiled in water $\left(100^{\circ} \mathrm{C}\right)$ for $30 \mathrm{~min}$. After cooling with running water, $2.5 \mathrm{~N} \mathrm{NaOH}$ was added to neutralize the solution. For soluble tannins, $80 \% \mathrm{MeOH}$ was used for extraction. Both total and soluble tannins in 'Mopan' and 'Yoho' persimmon fruit were determined according to the Folin-Denis method (Taira, 1996). Diluted sample solution extract (1 mL) in $6 \mathrm{~mL}$ of distilled water was mixed to $0.5 \mathrm{~mL}$ of $1 \mathrm{~N}$ Folinciocalteu reagent. After $3 \mathrm{~min}, 1 \mathrm{~mL}$ of saturated sodium carbonate $\left(\mathrm{Na}_{2} \mathrm{CO}_{3}\right)$ was added to the mixture along with $1.5 \mathrm{~mL}$ of distilled water. After shaking vigorously, the mixture was kept in the dark at room temperature for $1 \mathrm{~h}$. The absorbance of the resultant blue color was measured at $725 \mathrm{~nm}$ using a spectrophotometer (UVmini-1240; Shimadzu Corp., Kyoto, Japan). Gallic acid was used for the calibration curve. Experiments were repeated three times independently.

MEASUREMENT OF ETHYLENE PRODUCTION AND RESPIRATION RATES. Randomly chosen 'Mopan' and 'Yoho' persimmon fruit (three replicates of 15 to 20 fruit) were sealed in a 1-L glass container for $30 \mathrm{~min}$ at $23^{\circ} \mathrm{C}$. Ten milliliters of headspace gas inside the glass container was collected for injection into an IR analyzer (HWF-1; Honglang Instrument Equipment Co., Henan, China) to determine the respiration rate. After being kept at $23{ }^{\circ} \mathrm{C}$ for $6 \mathrm{~h}$, ethylene production was measured when 1 $\mathrm{mL}$ of headspace gas was taken and injected in a gas chromatographer (model GC9790II; Fuli Analysis Instrument Co., Jiangsu, China) that was equipped with a flame ionization detector (FID). Temperatures of the gasifier, FID, and oven were set as 140,200 , and $90{ }^{\circ} \mathrm{C}$, respectively, for ethylene measurement. The carrier flow rates of the gas used were 30, 30, and $300 \mathrm{~mL} \cdot \mathrm{min}^{-1}$ for nitrogen, hydrogen, and air, respectively. Ethylene production at storage days $0,1,2,4,7,10,12,15$, and 20 was calibrated with authentic ethylene gas standards, and the results were expressed as nanograms per kilogram per second. The respiration rate at storage days $0,4,7,10,15$, and 20 was calculated using a $\mathrm{CO}_{2}$ calibration curve and expressed as milligrams per kilogram per hour $\mathrm{CO}_{2}$.

RNA PREPARATION. Fifteen to 20 fruit were taken after 0, 4, 10 , and $20 \mathrm{~d}$ of fruit storage. After skin removal, the flesh was sampled by taking four wedges from each fruit, with each wedge constituting approximately one-eighth of the fruit. The flesh was quickly frozen in liquid nitrogen and ground to a fine powder; then, it was stored at $-80^{\circ} \mathrm{C}$. Total RNA in persimmon fruit tissues was extracted using a modified cetyltrimethylammonium bromide (CTAB) method as described by Gasic et al. 
(2004). RNA extraction was conducted with three biological repeats and three technical repeats in each sample.

REAL-TIME POLYMERASE CHAIN REACTION. The relative abundance of the transcripts was analyzed by real-time polymerase chain reaction (PCR). Total RNA was reverse-transcribed with the PrimeScript ${ }^{T M}$ RT reagent Kit with gDNA Eraser (TaKaRa Biomedical, Dalian, China). Quantitative real-time reversetranscription PCR (RT-PCR) was performed using SYBR ${ }^{\circledR}$ Premix Ex Taq $^{\text {TM }}$ II kit (TaKaRa Biomedical) and was performed using a CFX384 Touch $^{\text {TM }}$ Real-Time PCR Detection System (Bio-Rad Laboratories, Hercules, CA) according to the manufacturer's instruction. Actin was used as an internal control (Akagi et al. 2009). The relative gene expression was calculated by the comparative $\mathrm{Ct}$ method (Li et al. 2017). The Dkß-gal1, DkPG1, DkPME1, and DkPDC2 specific primers have been described by Wang et al. (2017). The DkXTH2specific and DkERF22-specific primers have been described by Zhu et al. (2013) and Min et al. (2014), respectively. Primers specific to DkETR1,DkETR2, DkERS1, and DkCTR1 have been described by Yin et al. (2012a). Primers specific to $D k A D H 1$, $D k P D C 1$, and DkERF19 have been described by Min et al. (2012). All primers are shown in Table 1. The RT-PCR was completed with three biological repeats and three technical repeats in each sample. All of the biological repeats showed consistent results, and the data for one of the replicates are presented in the figures. Each data point is the mean value obtained from the RT-PCR performed in triplicate on one sample, with error bars representing the SD.

Statistical analysis. The same experiment was performed in 2016 and 2017, with consistent results, and the data of 2016 are presented in this work. All experiments were conducted with three biological repeats and three technical repeats in each sample. All data were processed using Microsoft Excel 2016 (Microsoft Corp., Redmond, WA). Analysis of variance of data was performed using IBM SPSS Statistics (version 20; IBM Corp., Armonk, NY) and GraphPad Prism (version 7.0; GraphPad Software, San Diego, CA). Treatment means were compared using the IBM SPSS Statistics Duncan's multiple range test $(P \leq 0.05)$.

\section{Results and Discussion}

Changes in Fruit COlORATION AND TSS CONTENT DURING 'Mopan' ANd 'Yoho' Persimmon Fruit STORAGE. As shown in
Fig. 1, 'Mopan' is bigger than 'Yoho', whereas the latter often has a more flattened fruit shape and deeper reddish-orange skin. Color is one of the major desirable characteristics that determines consumer acceptance of a product. The $L, a$, and $b$ values were further evaluated regarding hue $\left(\mathrm{h}^{\circ}\right)$ and chroma $(\mathrm{C})$ color to ascertain their effects on the total color changes. As shown in Fig. 2A, the hue angle, which shows orange coloring of 'Yoho' and 'Mopan' persimmon, decreased gradually during storage. It indicates that the skin color of persimmon fruit were reddishyellow, and 'Yoho' (hue $=63.83 \pm 3.86$ ) had a deeper reddishorange skin compared with 'Mopan' (hue $=71.47 \pm 1.67 ; 90^{\circ}$ means that the persimmon is yellow and $0^{\circ}$ indicates it is completely red). This may due to the accumulation of carotenoid contents (Khoo et al., 2011). Lee et al. (2012) reported that ethylene affected carotenoid biosynthesis and additional ripening phenotypes via SlERF6 in tomato (Solanum lycopersicum L.). Generally, fruit with high chroma (Fig. 2B) values are more vivid than those with low values, even with the same hue angle. Chroma values of 'Yoho' and 'Mopan' persimmon fruit increased, meaning that the fruit were more vivid in color, as storage time increased. Concurrently, the lightness [ $L$-value (Fig. 2C)] decreased over 'Yoho' and 'Mopan' persimmon storage.

Figure 2D displays that the TSS of 'Mopan' persimmon decreased gradually but increased in 'Yoho' with storage time. The TSS content of 'Mopan' fruit was $15.1 \%$ immediately after harvest, and it decreased to $12.2 \%$ at $20 \mathrm{~d}$. This finding agreed with the information reported by Tilahun et al. (2017) regarding 'Daebong' persimmon. The TSS content of 'Yoho' fruit increased from $14 \%$ to $15.9 \%$ after 20 d. Candir et al. (2010) reported that the TSS content in nonastringent type persimmons such as 'Fuyu' and 'Jiro' increased during storage. However, 'Yoho' and 'Mopan' persimmon fruit showed different trends in TSS content changes during storage. Arnal and Del Río (2003) observed decreased TSS in 'Rojo brillante' persimmon (PCA) fruit, and they also found that the decrease in TSS contents in persimmon fruit was closely related to the changes in tannins from soluble to insoluble with $\mathrm{CO}_{2}$ treatment, but the mechanism responsible for this is still unclear. The different tannin metabolisms of astringent and nonastringent persimmon fruit (Ikegami et al., 2005) may be associated with the differences in TSS. The higher weight loss rate of 'Yoho' fruit (15.30\% loss at the end of the storage period) compared with

Table 1. Primers and DNA sequences used for the real-time polymerase chain reaction analysis.

\begin{tabular}{|c|c|c|c|}
\hline Gene & Forward primer $\left(5^{\prime}-3^{\prime}\right)$ & Reverse primer $\left(5^{\prime}-3^{\prime}\right)$ & Reference \\
\hline$\overline{\text { DkActin }}$ & CATGGAGAAAATCTGGCATCATAC & GAAGCACTGGGTGCTCTTCTG & Akagi et al., 2009 \\
\hline$D k P G 1$ & GCCCCATTGTCCTTGAATCAGAGA & GAATCATAACCAGCCTTCTATTTTTG & Wang et al., 2017 \\
\hline DkXTH2 & ACGCCAAGTTCTGCGACAC & GGGTATCGCTTCCTGTCG & Zhu et al., 2013 \\
\hline DkETR1 & CGTCATGAAAGGCCATTAGTGG & CCATTCAGGCTTGAGCAATTCT & Yin et al., 2012a \\
\hline DkETR2 & AGATGCCTGCAGATTGGCATGA & GCAAGGCTGTGTTCACCATGGC & Yin et al., 2012a \\
\hline DkCTR1 & GGCTTGTAACCCCACCAATA & CCATTGAAGCCCAGAGAAAC & Yin et al., $2012 \mathrm{a}$ \\
\hline$D k A D H 1$ & GAGAAGTTCATCACGCACGA & ACCAACTTGAGCCACCACTC & Min et al., 2012 \\
\hline$D k P D C 1$ & CCCATAACAGTTCCGAGAAA & CTGCACCATCAACTGCAAAT & Min et al., 2012 \\
\hline$D k P D C 2$ & CCCCACCAAATCCTCAGTAA & CCAGAAAAGATGGGCACAAA & Wang et al., 2017 \\
\hline$D k E R F 19$ & CCCAGACTCAAAGTATCTGATGA & AAAGACAGGGACATAAGAGAAGG & Min et al., 2012 \\
\hline$D k E R F 22$ & GCAGTAAGAAGCCAAGAATCAT & GAAAAACTGGAGCCGATAGAG & Min et al., 2014 \\
\hline
\end{tabular}



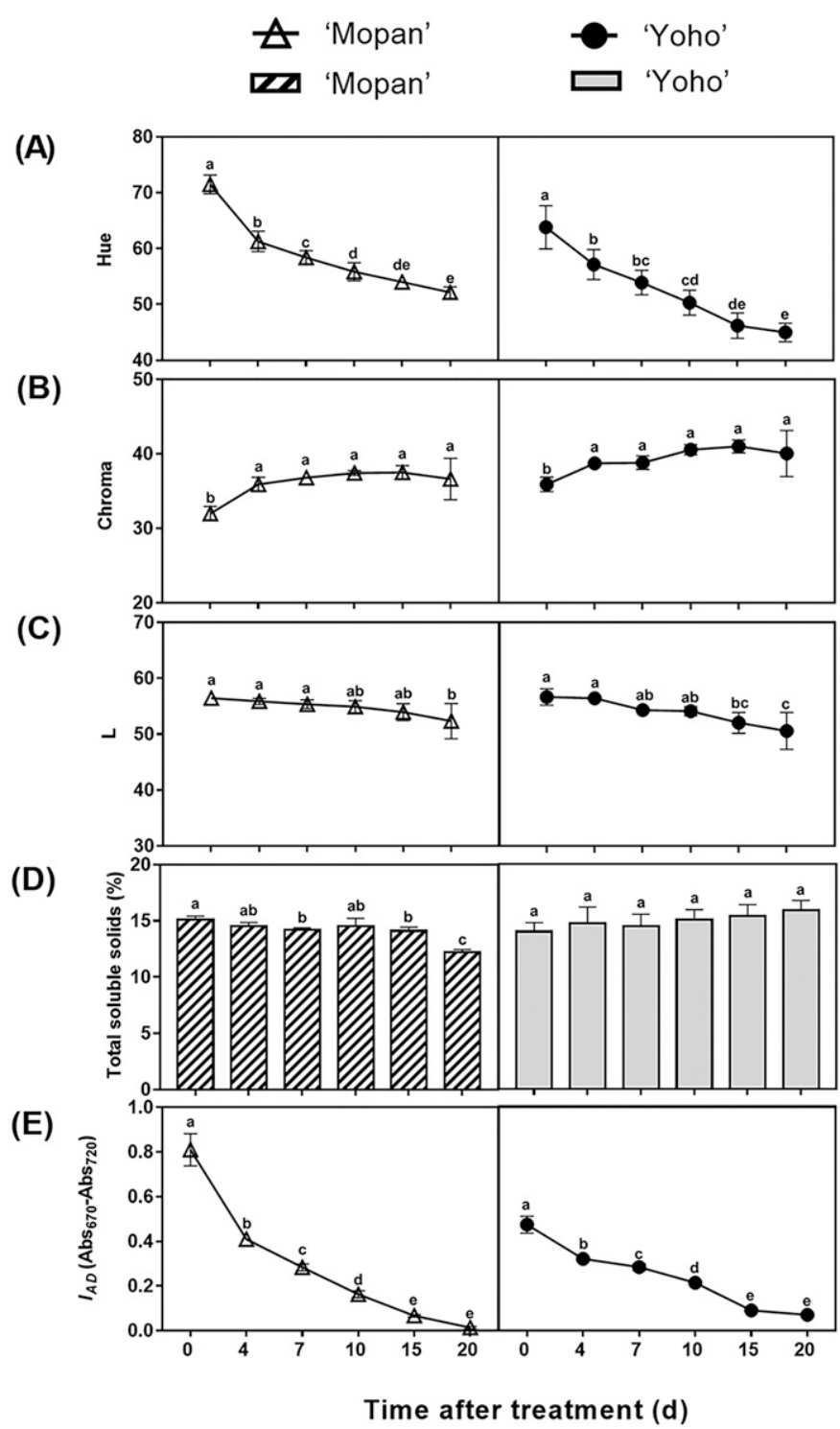

Fig. 2. Changes in lightness $(\mathbf{A})$, hue angle $(\mathbf{B})$, chroma $(\mathbf{C})$, total soluble solids (D), and index of absorbance difference $\left(I_{A D}\right)(\mathrm{E})$ of astringent 'Mopan' and nonastringent 'Yoho' persimmon fruit during storage at 22 to $25^{\circ} \mathrm{C}$. Error bars represent \pm SD for three replicates. The statistical differences between different time points are not significantly different according to Duncan's multiple range test $(P<0.05)$. $0 \mathrm{~d}$ means the samples were taken or tested immediately at the beginning of storage.

that of 'Mopan' fruit $(10.17 \%$ loss at the end of the storage period) during shelf life could also be related to these observed differences in TSS (Supplemental Fig. 1). It might be interesting to analyze the TSS and color effects with related gene expression changes in the current study. However, the changes do not directly lead to persimmon fruit softening and deastringency during postharvest; they indirectly influence them through signal transmission in fruit. Only firmness, total and soluble tannin contents, ethylene production, and respiration rate-related gene expression changes were included to explore the roles of cell wall-hydrolyzing enzymes, the de-astringent process, and endogenous ethylene in postharvest ripening.

The DA meter is a new tool used to assess the maturation state of stored fruit to provide information about the shelf life that can be predicted by measuring absorbance within the chlorophyll absorption range. The instrument provides an $I_{A D}$, which is calculated as the absorbance at $670 \mathrm{~nm}$ minus the absorbance at $720 \mathrm{~nm}$. High correlations between the $I_{A D}$ index and ripeness level have been reported for apple [Malus domestica Borkh. (Nyasordzi et al., 2013)], pear [Pyrus communis L. (Wang and Sugar, 2015)], and peach [Prunus persica L. (Ziosi et al., 2008)]. This is the first report of its use to predict ripening of persimmon. In our analysis, 'Mopan' and 'Yoho' persimmon fruit showed the same trend as $I_{A D}$ changes (Fig. 2E). $I_{A D}$ changes correlated with changes in hue angle $\left(R^{2}=\right.$ 0.9976 for 'Mopan'; $R^{2}=0.9888$ for 'Yoho'), chroma $\left(R^{2}=0.8521\right.$ for 'Mopan'; $R^{2}=0.8289$ for 'Yoho'), lightness $\left(R^{2}=0.7203\right.$ for 'Mopan'; $R^{2}=0.8807$ for 'Yoho'), and TSS of 'Yoho' $\left(R^{2}=\right.$ $0.9175)$. TSS of 'Mopan' $\left(R^{2}=0.5058\right)$ was not consistently related to measured $I_{A D}$ values. This demonstrates that $I_{A D}$ values that may be found in the future could provide some indication of "color" of both cultivars and "sweetness" of Yoho persimmon. The $I_{A D}$ was a reliable parameter for assessing fruit maturity at harvest nondestructively and predicting persimmon fruit behavior in storage. It can be a useful tool for assessing the maturation state of the persimmon fruit during storage and providing information about the shelf life that can be expected. Furthermore, it can help select the most ripened fruit to sell at the retail stage. Measurements of the $I_{A D}$ can also be used on a sorting line, which can provide an optimal distribution of persimmon fruit for storage.

ChANGES IN FRUIT FIRMNESS AND CELL WALL GENE EXPRESSION DURING 'MOPAN' AND 'YOHO' PERSIMMON FRUIT STORAGE. Fruit firmness is one of the most important features used to assess the progress of fruit ripening after harvest because it directly affects fruit quality and storage life. Figure $3 \mathrm{~A}$ and $\mathrm{B}$ showed that the firmness of 'Mopan' fruit was obviously lower than 'Yoho' and decreased rapidly after $10 \mathrm{~d}$. The correlation between $I_{A D}$ and firmness was $R^{2}=0.6461$ and $R^{2}=0.7581$ for 'Mopan' and 'Yoho' fruit, respectively. Farneti et al. (2015) also found that the $I_{A D}$ values were significantly linked with apple firmness. Cell wall-modifying enzymes such as polygalacturonase $(P G)$, pectin methyl esterase $(P M E), \beta$-galactosidase $(\beta-G a l)$, and xyloglucan endotransglycosylase/hydrolase $(X T H)$ are closely related to fruit softening according to previous studies $(\mathrm{Hu}$ et al., 2009; Wang et al., 2017). In the present study, the expression of four selected genes related to fruit softening, $D k P G 1, D k X T H 2, D k P M E 1$, and $D k \beta-G A L 1$, were detected up to $20 \mathrm{~d}$ during 'Yoho' and 'Mopan' persimmon storage, and similar trends were observed in both cultivars (Fig. 3C-F). The gene expression peaks of $D k P G 1, D k X T H 2$, and $D k \beta-G A L 1$ appeared around day 4, and DkPME1 showed increasing expression levels as early as day 0 for 'Mopan' persimmon. The gene expressions of DkPG1 and DkPME1 in 'Mopan' fruit were higher than those in 'Yoho' fruit.

Decreased fruit firmness is the result of a series of orderly adjustments applied by the related enzymes in a controlled manner (Huber, 1983). DkPG1, DkXTH2, DkPME1, and DkBGAL1 genes could be considered molecular markers for firmness, and the overexpression of these genes was correlated with increased fruit softening (Wang et al., 2017). Pectin is one of the main constituents of the primary cell walls and middle lamella of higher plants. The activities of the pectin-degrading enzymes polygalacturonase $(P G)$ and pectin methyl esterase $(P M E)$ have been found to be closely related to the degradation of pectins, which played a significant role in the softening 

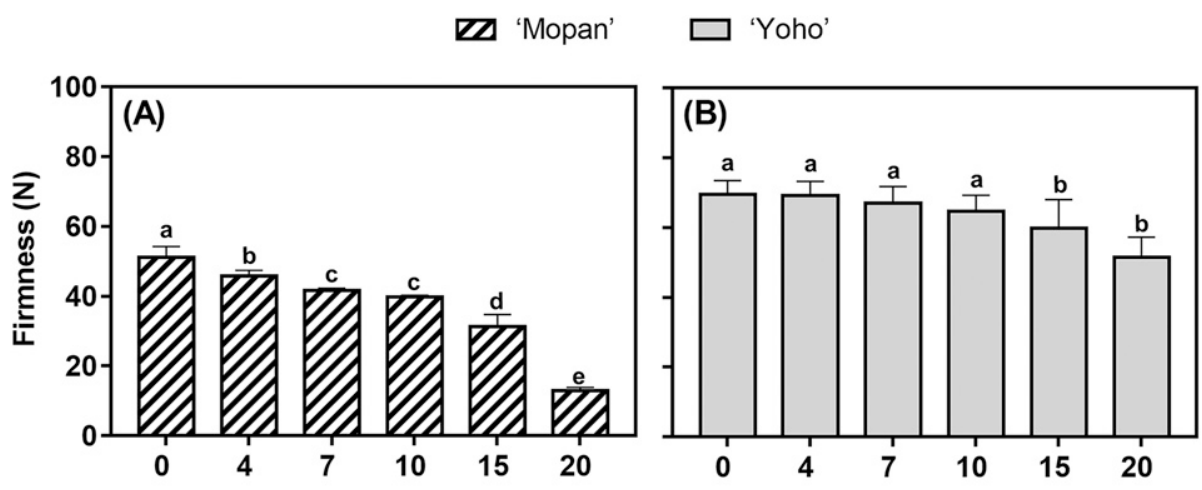

Time after treatment (d)
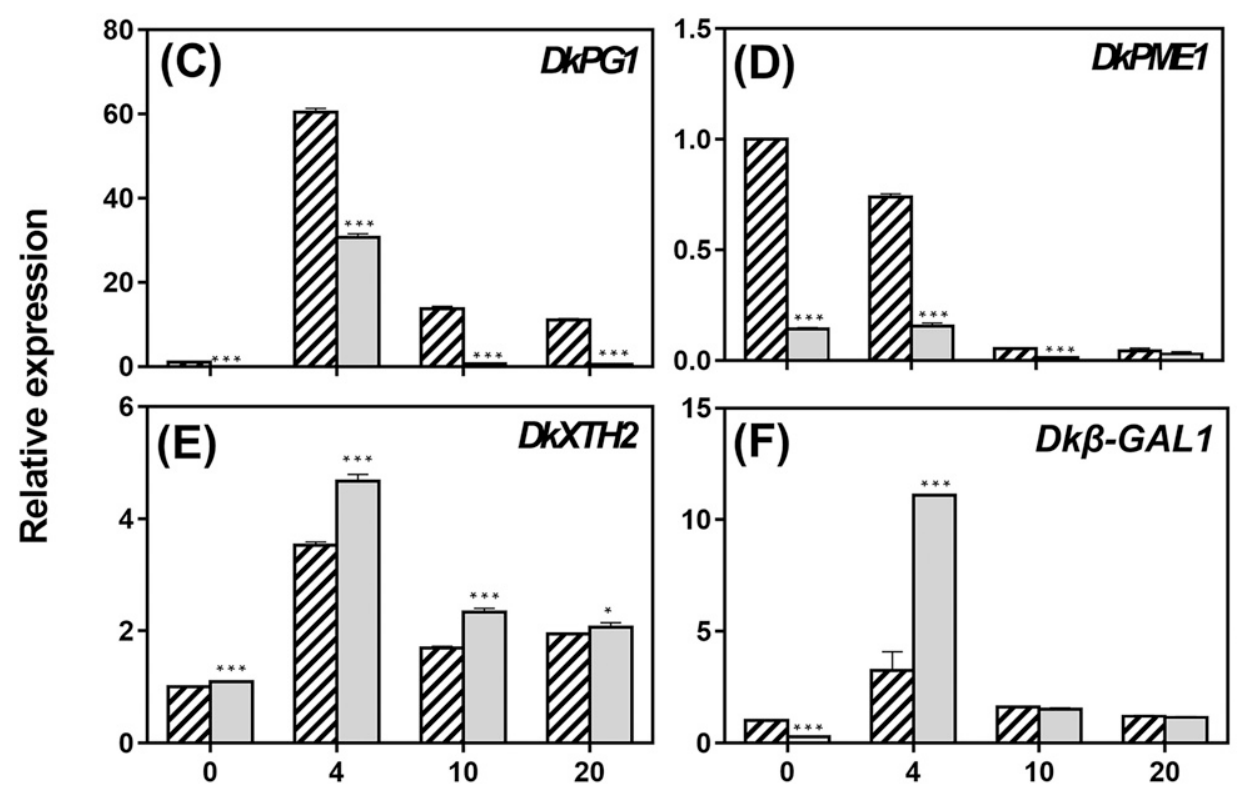

\section{Time after treatment (d)}

Fig. 3. Changes in firmness of astringent 'Mopan' (A) and nonastringent 'Yoho' (B) persimmon fruit and relative expression levels of cell wall hydrolase genes ( $D k P G 1, D k X T H 2, D k P M E 1$, and $D k \beta$-GAL1) during storage at 22 to $25^{\circ} \mathrm{C}$. Error bars represent $\pm \mathrm{SD}$ for three replicates. The statistical differences between different time points are not significantly different according to Duncan's multiple range test $(P<0.05)$. The two-tailed $t$ test was used to identify the statistical differences $\left(* P \leq 0.05,{ }^{*} P \leq 0.01\right.$, and $\left.* * * P \leq 0.001\right)$ between gene expression of 'Mopan' and 'Yoho'. $0 \mathrm{~d}$ means the samples were taken or tested immediately at the beginning of storage.

changes in fruit and vegetable tissues (Rodoni et al., 2010). $P M E$, the enzyme involved in pectin metabolism, catalyzes the demethylesterification of cell wall polygalacturonans to generate demethylated pectins that can be more easily hydrolyzed by $P G$ (Micheli, 2001). $P G$ hydrolyzes pectin acid along with the main chain of polygalacturonic acid, thereby causing cell wall dissolution and, ultimately, fruit softening. The advance work of DkPME1 may greatly affect the softening of persimmon fruit. At the same time, higher accumulation of $D k P G 1$ and $D k P M E 1$ in 'Mopan' fruit may be the main reason for 'Mopan' fruit softening (Jiang et al., 2010; Luo, 2007).

Changes In FRUIT SOLUble tanNins AND total tanNins CONTENT AND TANNINS-RELATED GENE EXPIRATION DURING 'Mopan' AND 'Yoho' Persimmon fruit storage. The total tannins and soluble tannins were used to evaluate the astringency level of persimmon fruit. The contents of the two forms of tannins of 'Mopan' and 'Yoho' fruit during storage are shown in Fig. 4A-D. The total tannin contents of both 'Mopan' and 'Yoho' fruit showed no notable changes during storage. However, values of 'Yoho' fruit began and remained distinctly lower than those of 'Mopan' fruit. Astringent-type fruit are rich in soluble tannins even at maturity, whereas the concentration of soluble tannins is significantly reduced during early development in fruit of the nonastringent type (Mo et al., 2016). Simultaneously, 'Yoho' fruit has a very low content of soluble tannins compared with 'Mopan' fruit. As shown in Fig. 4C and D, 'Mopan' fruit showed a dramatic decline in soluble tannins, but no significant changes were observed in the soluble tannin content of 'Yoho' fruit during the same period. Total tannins are composed of both soluble and insoluble tannins. The coagulation of soluble tannins to insoluble tannins most likely accounts for the natural loss of astringency (Mo et al., 2016). During this process, the total tannin barely changes. For 'Mopan' persimmon, the changes in $I_{A D}$ were directly proportional to changes in soluble tannins concentration $\left(R^{2}=\right.$ 0.7069). $I_{A D}$ could be an effective tool for predicting the degree of deastringency with noninvasive detection. Mo et al. (2016) reported that the soluble tannin contents of J-PCNA showed a trend similar to that of 'Mopan' and were always significantly lower than those of 'Mopan' during fruit development. Our results also showed that the two cultivars kept the same trend even after harvest.

The loss of astringency of persimmon fruit is largely due to the reversible interconversion of ethanol and acetaldehyde catalyzed by $A D H$ and $P D C$ enzymes (Mo et al., 2016). The expression of de-astringency-related genes $D k A D H 1$, $D k P D C 1$, and $D k P D C 2$ were studied during 'Mopan' and 'Yoho' persimmon storage (Fig. 4E-G). For 'Mopan' and 'Yoho' fruit, $D k A D H 1$ showed a relatively higher expression at day 0 , which decreased at day 4 , and an increasing trend was observed at day 10. Similarly, the expression levels of $D k P D C 2$ showed an obvious increase, and the peak occurred concomitantly with an advanced ripening stage at day 4 . However, the $D k P D C 1$ expression peak occurred at day 4 for 'Yoho' fruit, but there were no significant changes in 'Mopan' fruit.

Previous studies of the physiology of de-astringency of persimmons indicated that $A D H$ and $P D C$ were associated with persimmon de-astringency and had key roles. $D k A D H$ and $D k P D C$ genes have been characterized from 'Mopan' persimmon by Min et al. (2012). The transient overexpression of the 

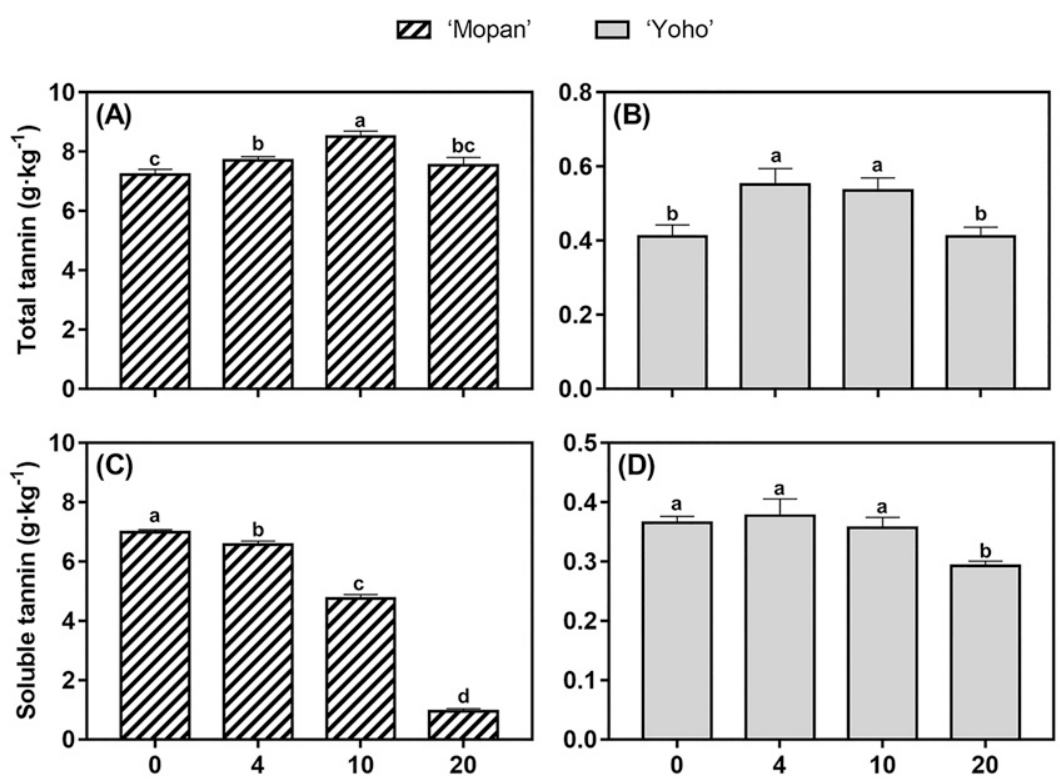

Time after treatment (d)
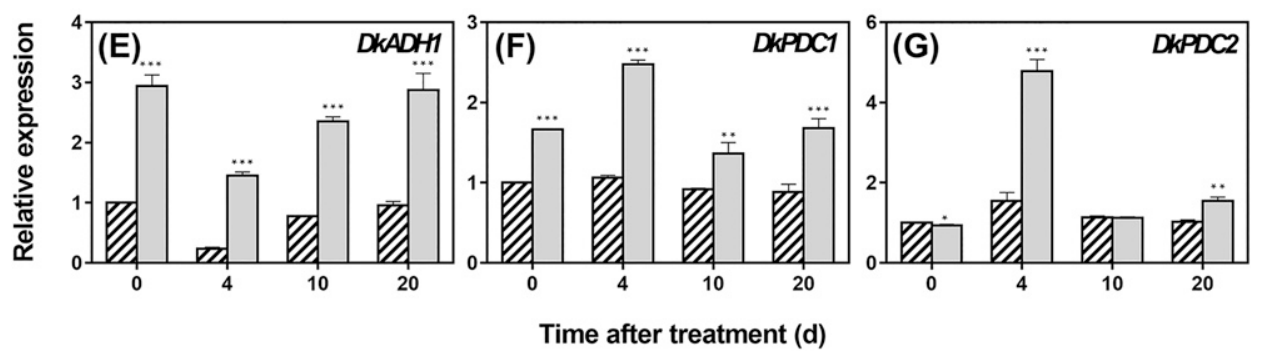

Fig. 4. Changes in soluble tannin and total tannin contents of astringent 'Mopan' $(\mathbf{A}, \mathbf{C})$ and nonastringent 'Yoho' (B, D) persimmon fruit and relative expression levels of de-astringent-related genes ( $D k A D H 1, D k P D C 1$, and $D k P D C 2)$ during storage at 22 to $25^{\circ} \mathrm{C}$. Error bars represent $\pm \mathrm{SD}$ for three replicates. The statistical differences between different time points are not significantly different according to Duncan's multiple range test $(P<0.05)$. The two-tailed $t$ test was used to identify the statistical differences $(* P \leq 0.05, * * P \leq 0.01$, and $* * * P \leq 0.001)$ between gene expression of 'Mopan' and 'Yoho'. 0 d means the samples were taken or tested immediately at the beginning of storage.

DkADH1 and DkPDC2 genes in 'Mopan' persimmon leaves caused a significant reduction in the levels of soluble tannins in the leaves (Mo et al., 2016). $\mathrm{CO}_{2}$ and ethylene treatment effectively increased the transcript abundance of $D k A D H 1$, $D k P D C 1$, and DkPDC2 (Min et al., 2012). However, under natural conditions and no treatment conditions, the expressions of $D k A D H 1, D k P D C 1$, and $D k P D C 2$ were almost constant during maturation, and this was also correlated with the slow process of natural de-astringency in 'Mopan' fruit without treatment. Similarly, the expression of DkADH1, DkPDC1, and $D k P D C 2$ genes in 'Yoho' fruit exhibited the same patterns. Despite the high expression of de-astringency genes of 'Yoho' fruit after harvest, the tannin content was still low. According to Mo et al. (2016), the natural astringency loss observed in 'Maekawa-jirou' (J-PCNA) is unrelated to tannin coagulation, which is similar to our findings for 'Yoho' (J-PCNA). Using RNA sequencing, Yin et al. (2012b) isolated another three $A D H$ genes and five $P D C$ genes from 'Mopan' persimmon that were induced by the de-astringent treatment, but the roles of these genes in de-astringency need further investigation.
ChANGeS IN FRUIT RESPIRATION AND ETHYLENE PRODUCTION AND ETHYLENERELATED GENE EXPIRATION DURING 'MOPAN' AND 'YOHO' PERSIMMON FRUIT STORAGE. Figure $5 \mathrm{~A}$ and $\mathrm{B}$ show that the respiration rates of 'Mopan' and 'Yoho' persimmon fruit decreased during the first $4 \mathrm{~d}$ of storage. After that, 'Mopan' fruit maintained a constant respiration rate, and no significant differences were detected. 'Yoho' fruit experienced an increase near the end of storage. Fruit continued to respire strongly after harvesting without any treatments. The respiration process not only consumes nutrients but also produces endogenous ethylene, which may accelerate fruit ripening and senescence (Abbas and Fandi, 2002). The respiration rate $\left(R^{2}=0.808\right.$ for 'Mopan' and $R^{2}=0.4776$ for 'Yoho') and ethylene production ( $R^{2}=0.7374$ for 'Mopan' and $R^{2}=$ 0.9102 for 'Yoho') showed a clear association with $I_{A D}$ values, thus indicating that $I_{A D}$ values may be a reliable nondestructive ethylene estimator and respiration monitor.

The changes in ethylene production for 'Mopan' and 'Yoho' persimmon fruit are shown in Fig. 5C and D; endogenous ethylene of persimmon was very low on the first day during storage; then, its production significantly and lineally increased. It peaked at $12 \mathrm{~d}$ of storage for 'Mopan' fruit. After 12 $\mathrm{d}$, the ethylene production started to significantly decrease. For 'Yoho' fruit, this peak was reached at $15 \mathrm{~d}$. Persimmon fruit are extremely sensitive to endogenous ethylene, although only a small amount of ethylene is generated during postharvest ripening. As previously reported, the response to endogenous ethylene was obvious during the ripening of 'Yoho' fruit (Yin et al., 2012a). According to our research, we found that 'Mopan' fruit are also sensitive to endogenous ethylene.

The natural expressions of six ethylene receptors and signal transduction genes (DkETR1, DkETR2, DkCTR1, DkERS1, $D k E R F 19$, and DkERF22) in 'Mopan' and 'Yoho' persimmon fruit have been selected and studied in the present experiments (Fig. 5E-J). 'Mopan' persimmon fruit were not sensitive to endogenous ethylene, and no significant differences were detected for 'Mopan' fruit gene expression after $20 \mathrm{~d}$ at 22 to $25{ }^{\circ} \mathrm{C}$. The expression of DkETR1, DkETR2, DkCTR1, and $D k E R S 1$ increased slightly during ripening; however, for $D k E R F 22$, no significant changes were detected. DkERF19 was the gene most sensitive to endogenous ethylene and showed the largest increase in its expression at $10 \mathrm{~d}$. Min et al., (2012) reported that $D k E R F 22$ rapidly responded to $\mathrm{CO}_{2}$ treatment, whereas $D k E R F 19$ exhibited delayed the accumulation 


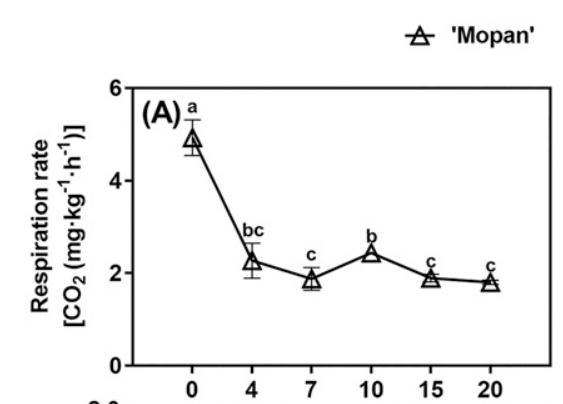

'Yoho'
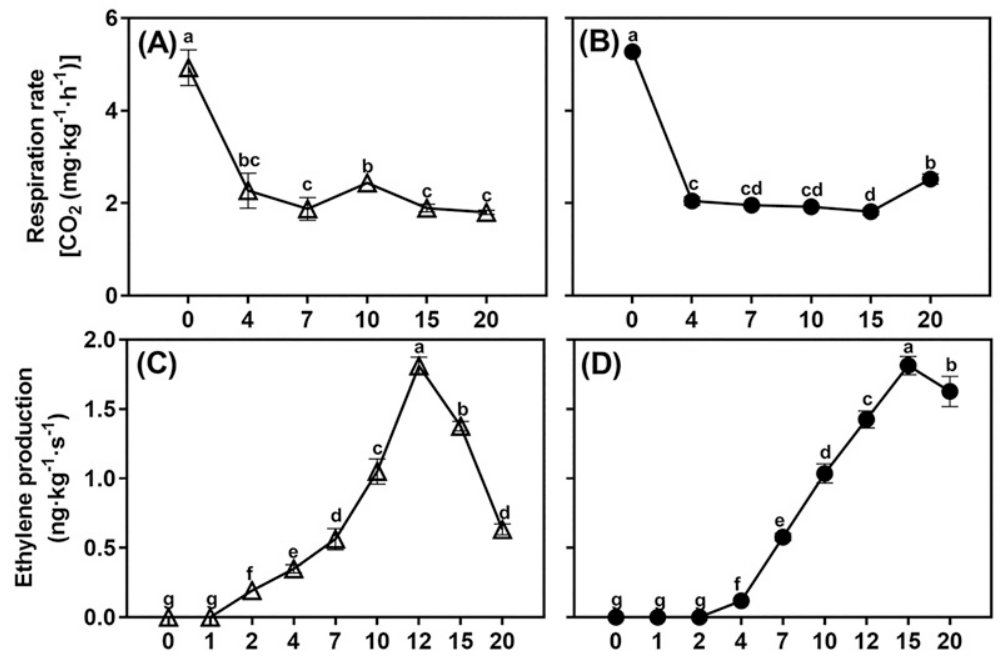

Time after treatment (d)

ZZ 'Mopan' $\square$ 'Yoho'
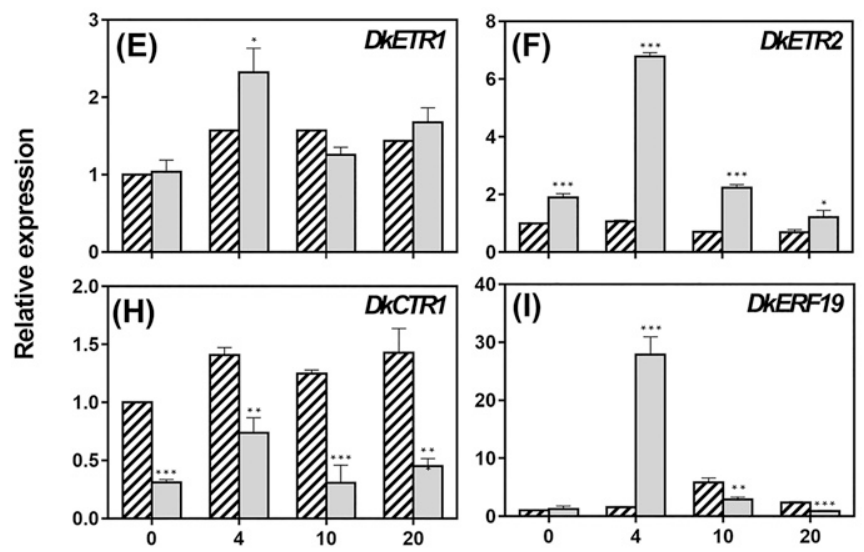

Time after treatment (d)

Fig. 5. Changes in respiration rate and ethylene production of astringent 'Mopan' $(\mathbf{A}, \mathbf{C})$ and nonastringent 'Yoho' (B, D) persimmon fruit and relative expression levels of ethylene signal genes (DkETR1, DkETR2, DkERS1, $D k C T R 1, D k E R F 19$, and DkERF22) during storage at 22 to $25^{\circ} \mathrm{C}$. Error bars represent \pm SD for three replicates. The statistical differences between different time points are not significantly different according to Duncan's multiple range test $(P<0.05)$. The two-tailed $t$ test procedure was used to identify the statistical differences $(* P \leq 0.05, * * P \leq 0.01$, and $* * * P \leq 0.001)$ between gene expression of 'Mopan' and 'Yoho'. 0 d means the samples were taken or tested immediately at the beginning of storage.

after $\mathrm{CO}_{2}$ treatment. This indicated that ethylene has different regulatory mechanisms under natural and hypoxic conditions. However, different from 'Mopan' fruit, 'Yoho' fruit does not readily soften after harvest, but endogenous ethylene still regulates the changes inside the fruit. For 'Yoho' fruit, the expression levels of ethylene signal-related genes increased significantly and peaked on day 4 (DkETR1, DkETR2, DkCTR1, $D k E R S 1$, and $D k E R F 19$ ) or day 10 (DkERF22). The expression changes of ethylene genes did not exactly follow the ethylene level dynamics in 'Mopan' and 'Yoho' fruit, and the same conclusion was obtained by a previous study (Yin et al., 2012a). After harvest, the ethylene signal genes in 'Yoho' fruit were expressed at constant levels (DkETR1,DkEIL1) or had a small increase in ethylene accumulation time (DkERS1, DkETR2, $D k C T R 1)$. More diversity in expression patterns of the $D k E R F$
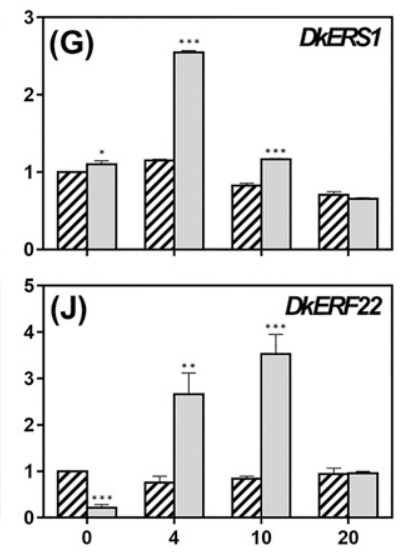

genes was observed. DkERF1, $D k E R F 6$, and DkERF7 increased during the early stages of storage. For 'Mopan' fruit, most of the ethylene signal genes were expressed at constant levels.

An analysis of the expression of ethylene receptor genes during ripening in many fruit does not follow a pattern consistent with the predicted model, indicating that more complex molecular mechanisms are operating in the regulation of ethylene perception during fruit ripening (Bapat et al., 2010). Ethylene receptors and transcription factors physically interact with the downstream signal transduction mechanisms.

Ethylene showed complex properties during fruit ripening regulation and worked through activation of the promoter to pass the signal downstream to the effector. A previous study indicated that $D k E R F s$ bind directly to the DkXTHO and regulate this gene, which encodes an important cell wall metabolism enzyme (Wang et al., 2017). Many comprehensive studies of 'Mopan' were performed to investigate the transactive work of ethylene and promoters involved in softening, but little work regarding the 'Yoho' fruit has been performed.

\section{Conclusions}

Mopan persimmon is an economically important cultivar commercially grown in northern China. During postharvest storage of astringent 'Mopan' persimmons at 22 to $25{ }^{\circ} \mathrm{C}$ for up to $20 \mathrm{~d}$, the regular changes to physiological properties include the following: endogenous ethylene production increased for $12 \mathrm{~d}$, followed by a sharp decrease; a decrease in the soluble tannin content to less than $0.2 \%$, which is the level at which fruit lose astringency; initial decline in respiration that then became constant and gradual decline in firmness; ethylene signal genes (DkETR1, DkETR2, DkCTR1, DkERS1, DkERF19, and DkERF22), deastringency genes $(D k A D H 1, D k P D C 1$, and $D k P D C 2)$, and cell wall hydrolase genes (DkPG1,DkXTH2, DkPME1, and $D k \beta-G A L 1)$ were all expressed at various levels, resulting in physiological and quality property changes in fruit over time. A transcriptome sequencing analysis was performed for 'Mopan' and 'Yoho' fruit after harvest at 0, 4, 10, and $20 \mathrm{~d}$ of storage and consistent data were obtained (data not shown, manuscript in preparation). Further studies are needed to clarify the gene families that are important for persimmon fruit ripening. 


\section{Literature Cited}

Abbas, M.F. and B.S. Fandi. 2002. Respiration rate, ethylene production and biochemical changes during fruit development and maturation of jujube (Ziziphus mauritiana Lamk). J. Sci. Food Agr. 82:1472-1476.

Akagi, T., A. Ikegami, T. Tsujimoto, S. Kobayashi, A. Sato, A. Kono, and $\mathrm{K}$. Yonemori. 2009. DkMyb4 is a Myb transcription factor involved in proanthocyanidin biosynthesis in persimmon fruit. Plant Physiol. 151:2028-2045.

Amal, S.H.A., M.M. El-Mogy, H.E. Aboul-Anean, and B.W. Alsanius. 2010. Improving strawberry fruit storability by edible coating as a carrier of thymol or calcium chloride. J. Hort. Sci. Ornam. Plants 2:88-97.

Arnal, L. and M.A. Del Río. 2003. Removing astringency by carbon dioxide and nitrogen-enriched atmospheres in persimmon fruit cv. "Rojo brillante". J. Food Sci. 68:1516-1518.

Bapat, V.A., P.K. Trivedi, A. Ghosh, V.A. Sane, T.R. Ganapathi, and P. Nath. 2010. Ripening of fleshy fruit: Molecular insight and the role of ethylene. Biotechnol. Adv. 28:94-107.

Candir, E., A.E. Özdemir, M. Kaplankiran, T.H. Demirkeser, and E. Yildiz. 2010. Storage life of non-astringent persimmons grown in the eastern Mediterranean. N. Z. J. Crop Hort. Sci. 38:1-6.

Chen, X.N., J.F. Fan, X. Yue, X.R. Wu, and L.T. Li. 2008. Radical scavenging activity and phenolic compounds in persimmon (Diospyros kaki L. cv. Mopan). J. Food Sci. 73:C24-C28.

Farneti, B., M.S. Gutierrez, B. Novak, N. Busatto, D. Ravaglia, F. Spinelli, and G. Costa. 2015. Use of the index of absorbance difference $\left(I_{A D}\right)$ as a tool for tailoring post-harvest 1-MCP application to control apple superficial scald. Scientia Hort. 190:110-116.

Food and Agriculture Organization of the United Nations. 2016. FAOSTAT. 2 Mar. 2020. <http://www.fao.org/faostat/en/\#data/ QC/visualize>.

Food and Agriculture Organization of the United Nations. 2018. FAOSTAT. 2 Mar. 2020. <http://www.fao.org/faostat/zh/\#data/IC>. Gasic, K., A. Hernandez, and S.S. Korban. 2004. RNA extraction from different apple tissues rich in polyphenols and polysaccharides for cDNA library construction. Plant Mol. Biol. Rpt. 22:437-438.

George, A.P. and S. Redpath. 2008. Health and medicinal benefits of persimmon fruit: A review. Adv. Hort. Sci. 22:244-249. <https:// www.jstor.org/stable/42883464>.

Guo, X.H., S.Z. Fang, J. Wang, X.X. Guo, L.Q. Xu, and L. Yuan. 2006. Study on the infection of the Mopan persimmon quality by carbon dioxide. Food Res Dev. 27:156-159. <http://www.cnki.com.cn/Article/ CJFDTotal-SPYK200608048.htm>.

Hu, F., S.S. Ma, J.S. Zhang, Q.M. Han, G. Zhao, and C.L. Wu. 2009. Effects of 1-methylcyclopropene on postharvest physiology and cell ultrastructure of pollination-constant and non-astringent persimmon during storage. Acta Hort. Sinica 36:487-492. <http://www.ahs.ac.cn/EN/Y2009/V36/I04/487>.

Huber, D.J. 1983. The role of cell wall hydrolases in fruit softening. Hort. Rev. 5:169-219.

Ikegami, A., A. Kitajima, and K. Yonemori. 2005. Inhibition of flavonoid biosynthetic gene expression coincides with loss of astringency in pollination-constant, non-astringent (PCNA)-type persimmon fruit. J. Hort. Sci. Biotechnol. 80:225-228.

Jiang, N.N., J.P. Rao, R.S. Fu, and J.T. Suo. 2010. Effects of propylene and 1-methylcyclopropene on PG activities and expression of $D k P G 1$ gene during persimmon softening process. Acta Hort. Sinica 37:1507-1512. <http://www.ahs.ac.cn/EN/Y2010/V37/I9/1507>.

Kato, K. 1990. Astringency removal and ripening in persimmons treated with ethanol and ethylene. HortScience 25:205-207.

Khoo, H.E., K.N. Prasad, K.W. Kong, Y. Jiang, and A. Ismail. 2011. Carotenoids and their isomers: Color pigments in fruits and vegetables. Molecules 16:1710-1738.

Lee, J.M., J.G. Joung, R. McQuinn, M.Y. Chung, Z. Fei, D. Tieman, H. Klee, and J. Giovannoni. 2012. Combined transcriptome, genetic diversity and metabolite profiling in tomato fruit reveals that the ethylene response factor SIERF6 plays an important role in ripening and carotenoid accumulation. Plant J. 70:191-204.

Li, D., Y.D. Cheng, Y. Dong, Z.L. Shang, and J.F. Guan. 2017. Effects of low temperature conditioning on fruit quality and peel browning spot in 'Huangguan' pears during cold storage. Postharvest Biol. Technol. 131:68-73.

Luo, Z.S. 2007. Effect of 1-methylcyclopropene on ripening of postharvest persimmon (Diospyros kaki L.) fruit. Lebensm. Wiss. Technol. 40:285-291.

Micheli, F. 2001. Pectin methylesterases: Cell wall enzymes with important roles in plant physiology. Trends Plant Sci. 6:414-419.

Min, T., F. Fang, H. Ge, Y.N. Shi, Z.R. Luo, Y.C. Yao, D. Grierson, X.R. Yin, and K.S. Chen. 2014. Two novel anoxia-induced ethylene response factors that interact with promoters of deastringency-related genes from persimmon. PLoS One 9(5), doi: 10.1371/journal.pone.0097043.

Min, T., X.R. Yin, Y.N. Shi, Z.R. Luo, Y.C. Yao, D. Grierson, I.B. Ferguson, and K.S. Chen. 2012. Ethylene-responsive transcription factors interact with promoters of $A D H$ and $P D C$ involved in persimmon (Diospyros kaki) fruit de-astringency. J. Expt. Bot. 63:6393-6405.

Ministry of Agriculture of the People's Republic of China. 2018. Persimmon science \& industry in central China. 2 Mar. 2020. $<\mathrm{http}: / /$ hzsy.hzau.edu.cn/info/1048/1430.htm>.

Mo, R.L., S.C. Yang, Y.M. Huang, W.X. Chen, Q.L. Zhang, and Z.R. Luo. 2016. $A D H$ and $P D C$ genes involved in tannins coagulation leading to natural de-astringency in Chinese pollination constant and non-astringency persimmon (Diospyros kaki Thunb.). Tree Genet. Genomes 12(17), doi: 10.1007/s11295-016-0976-0.

Nyasordzi, J., H. Friedman, Z. Schmilovitch, T. Ignat, A. Weksler, I. Rot, and S. Lurie. 2013. Utilizing the $I_{A D}$ index to determine internal quality attributes of apples at harvest and after storage. Postharvest Biol. Technol. 77:80-86.

Pang, J.H., B. Ma, H.J. Sun, G.I. Ortiz, S. Imanishi, S. Sugaya, H. Gemma, and H. Ezura. 2007. Identification and characterization of ethylene receptor homologs expressed during fruit development and ripening in persimmon (Diospyros kaki Thumb.). Postharvest Biol. Technol. 44:195-203.

Rodoni, L., N. Casadei, A. Concellon, A.R. Chaves Alicia, and A.R. Vicente. 2010. Effect of short-term ozone treatments on tomato (Solanum lycopersicum L.) fruit quality and cell wall degradation. J. Agr. Food Chem. 58:594-599.

Saltveit, M.E. 1999. Effect of ethylene on quality of fresh fruits and vegetables. Postharvest Biol. Technol. 15:279-292.

Strommer, J. 2011. The plant $A D H$ gene family. Plant J. 66:128-142. Taira, S. 1996. Astringency in persimmon, p. 97-110. In: H.P. Linskens and J.F. Jackson (eds.). Modern methods of plant analysis. Vol. 18. Fruit analysis. Springer-Verlag, Berlin/Heidelberg, Germany.

Taira, S., K. Ikeda, and K. Ohkawa. 2001. Comparison of insolubility of tannins induced by acetaldehyde vapor in fruits of three types of astringent persimmon. J. Jpn. Soc. Food Sci. 48:684-687.

Tanaka, T., R. Takahashi, I. Kouno, and G.I. Nonaka. 1994. Chemical evidence for the de-astringency (insolubilization of tannins) of persimmon fruit. J. Chem. Soc., Perkin Trans. 1 20:3013-3022.

Tilahun, S., J.Y. Heo, and C.S. Jeong. 2017. Quality and expression of ethylene response genes of 'Daebong' persimmon fruit during ripening at different temperatures. Postharvest Biol. Technol. 133:57-63.

Wang, M.M., Q.G. Zhu, C.L. Deng, Z.R. Luo, N.J. Sun, D. Grierson, X.R. Yin, and K.S. Chen. 2017. Hypoxia-responsive ERFs involved in postdeastringency softening of persimmon fruit. Plant Biotechnol. J. 15:1409-1419.

Wang, Y. and D. Sugar. 2015. 1-MCP efficacy in extending storage life of 'Bartlett' pears is affected by harvest maturity, production elevation, and holding temperature during treatment delay. Postharvest Biol. Technol. 103:1-8.

Watkins, C.B. 2008. Overview of 1-methylcyclopropene trials and uses for edible horticultural crops. HortScience 43:86-94. 
Yakushiji, H. and A. Nakatsuka. 2007. Recent persimmon research in Japan. Jpn. J. Plant Sci. 1:42-62.

Yamada, M., G. Edgardo, and Y. Keizo. 2012. Cultivars released from the NIFTS breeding program in Japan, p. 681-683. In: M.L. Badenes and D.H. Byrne (eds.). Fruit breeding. Vol. 8. Springer, New York, NY. Yamada, M., S. Taira, M. Ohtsuki, A. Sato, H. Iwanami, H. Yakushiji, R.Z. Wang, Y. Yang, and G.C. Li. 2002. Varietal differences in the ease of astringency removal by carbon dioxide gas and ethanol vapor treatments among Oriental astringent persimmons of Japanese and Chinese origin. Scientia Hort. 94:63-72.

Yamane, H., A. Kurihara, K. Nagata, M. Yamada, T. Kishi, K. Yoshinaga, R. Matsumoto, K. Kanato, T. Sumi, T. Hirabayashi, and T. Ozawa. 1991. New Japanese persimmon [Diospyros kaki] cultivar "Youhou". Bul. Fruit Tree Res. Sta. (Japan) 20:49-61.

Yin, X.R., Y.N. Shi, T. Min, Z.R. Luo, Y.C. Yao, Q. Xu, I. Ferguson, and K.S. Chen. 2012a. Expression of ethylene response genes during persimmon fruit astringency removal. Planta 235:895-906.

Yin, X., T. Min, Y. Shi, and K. Chen. 2012b. Isolation of novel hypoxia responsive persimmon $A D H, P D C$ and $E R F$ genes using $R N A$-Seq. Acta Hort. 996:405-409.
Yonemori, K. and J. Matsushima. 1985. Property of development of the tannin cells in non-astringent type fruits of japanese persimmon (Diospyros kaki) and its relationship to natural deastringency. J. Jpn. Soc. Hort. Sci. 54:201-208.

Zhang, P., J. Li, S.H. Chen, P. Zhang, and Z.J. Zhou. 2012. Screen the de-astringent optimal condition of Mopan persimmon. Food Sci. Technol. 10:66-70.

Zhu, Q.G., J.P. Rao, H.Y. Tian, and Y. Han. 2012. Effects of 1-methylcyclopropene and propylene on expression of XTH genes in persimmon fruits. Acta Hort. Sinica 39:1278-1284. <http://www. ahs.ac.cn/EN/Y2012/V39/I7/1278>

Zhu, Q.G., Z.K. Zhang, J.P. Rao, D.J. Huber, J.Y. Lv, Y.L. Hou, and K.H. Song. 2013. Identification of xyloglucan endotransglucosylase/ hydrolase genes $(X T H s)$ and their expression in persimmon fruit as influenced by 1 -methylcyclopropene and gibberellic acid during storage at ambient temperature. Food Chem. 138:471-477.

Ziosi, V., M. Noferini, G. Fiori, A. Tadiello, L. Trainotti, G. Casadoro, and G. Costa. 2008. A new index based on vis spectroscopy to characterize the progression of ripening in peach fruit. Postharvest Biol. Technol. 49:319-329. 


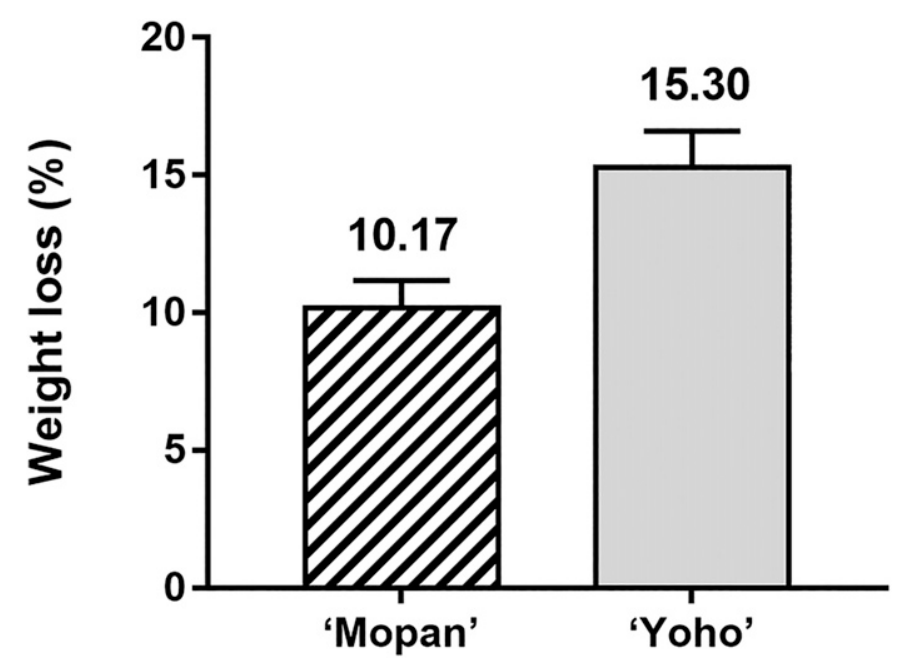

Supplemental Fig. 1. Weight loss of 'Mopan' and 'Yoho' persimmon fruit at the end of the storage period (day 0 to day 20). 